Federal Reserve Bank of Minneapolis

Research Department

\title{
Models of Sovereign Debt: Partial vs. General Reputations
}

\author{
Harold L. Cole and Patrick J. Kehoe* \\ Working Paper 580
}

March 1997

\begin{abstract}
Bulow and Rogoff (1989b) show that as long as governments can earn the market rate of return by saving abroad, standard reputation models cannot support debt. We argue that these standard reputation models are partial in the sense that actions of agents in one arena affect reputation in that arena only. We develop a general model of reputation in which if a government is viewed as untrustworthy in one relationship, this government will be viewed as untrustworthy in other relationships. We show that our general model of reputation can support large amounts of debt.
\end{abstract}

*Cole, Federal Reserve Bank of Minneapolis; Kehoe, Federal Reserve Bank of Minneapolis and University of Minnesota. Kehoe thanks the National Science Foundation and the Ronald S. Lauder Foundation for research support. The views expressed herein are those of the authors and not necessarily those of the Federal Reserve Bank of Minneapolis or the Federal Reserve System. 


\section{INTRODUCTION}

The standard reputation argument for why sovereign governments repay debts is that governments fear that if they default, their tarnished reputations will spill over to future debt relationships and make bankers less willing to lend to them. (See, for example, Eaton and Gersovitz 1981; Kletzer 1984; Manuelli 1986; Grossman and Van Huyck 1988; Atkeson 1991; and Cole, Dow, and English 1995.) Bulow and Rogoff (1989b) challenge this traditional explanation. In a provocative paper, they show that "under fairly general conditions, lending to small countries must be supported by the direct sanctions available to creditors, and cannot be supported by a country's 'reputation for repayment'" (1989b, p. 43). A key reason for the difference between this result and the results in the rest of the literature is that Bulow and Rogoff assume that regardless of its past behavior, a government can earn the market rate of return on its savings by saving with foreign bankers (possibly with full sets of state-contingent contracts and state-contingent payoffs). ${ }^{1}$ The rest of the literature, either explicitly or implicitly, assumes that if a country defaults, it cannot save.

If we accept the Bulow and Rogoff argument that their assumption is the empirically relevant one, then it might seem that the only explanation of why countries do not default is that there are large direct sanctions for so doing. The empirical case for large direct sanctions, however, is weak. In the nineteenth century there are examples in which debt repayment was enforced by direct use of force and sanctions, however, in the twentieth century there is little evidence of such a means of enforcement. (English 1996 carefully describes the historical details.) This evidence suggests that direct sanctions cannot explain why countries repay their debts.

We argue that even under the Bulow and Rogoff assumption, reputation arguments for repayment of debt can be revived. The standard reputation models that Bulow and Rogoff dismiss are partial in the sense that actions of agents in one arena of behavior affect reputation in that arena only. In this debt literature if a government defaults on a loan, it ruins its reputation only in the debt arena. We develop a general model of reputation in which a government's actions in the debt arena 
must spill over to a different arena in which trust is important. The basic idea of the paper is that if a government is viewed as untrustworthy in one relationship, this government will be viewed as untrustworthy in other relationships. Viewed this way, the benefits of maintaining a good relationship in one arena cannot be calculated simply by looking at that arena alone. Instead, account must be taken of the ramifications in a variety of other arenas, which, at least on the surface, may not seem to be directly connected to the original arena, where misbehavior might occur.

An example of what we have in mind is provided by events in Peru in the 1980s. When President Alan Garcia came to power in 1985, Peru faced a heavy external debt burden. He immediately limited the foreign debt payments to 10 percent of exports and unilaterally revoked the existing contracts of the foreign oil companies, eventually nationalizing one of them. Discussions in the popular press at the time talk about how these actions by President Garcia called into question his respect for property rights more generally. During this same period capital flight accelerated. Subsequently, in 1987 Garcia came up with a plan to nationalize the banks and the insurance companies. Our interpretation of these events is that Garcia's reputation for respecting property and contract rights was so damaged by his initial actions that, despite the fact that they implied a reduced need for government revenue in the future, investors decided to relocate their assets abroad. Subsequent events suggest that these fears were justified.

There are many examples of other arenas in which governments are engaged in trust relationships. Examples of such different arenas include ones in which either foreign or domestic agents are investing time and resources with the implicit understanding that the government will not tax the returns to their investments too heavily. For example, when a foreign oil company makes upfront investments in Peru, it is trusting the government to not decide ex-post to tax its investments more heavily than promised. Likewise when domestic residents in Mexico make up-front investments in, say, a tortilla shop, they are trusting the government to not decide ex-post to tax their returns more heavily than promised. Of course, these investments can as well be human capital investments which 
involve time as well as resources. Another class of examples is typified by a mutual defense pact, such as NATO, in which governments sign agreements to come to each other's aid under certain conditions. Clearly there is an element of trust in such a relationship.

In this paper, we develop a general model of a country's reputation in which misbehavior in the debt arena tarnishes a government's reputation in other arenas. We find that spillovers in reputation from the debt relationship to the other relationships can indeed support debt. To set up our later analysis, we begin by reviewing the analysis of Cole and Kehoe (1995), which shows how the Bulow and Rogoff result involving the nonexistence of trigger strategy equilibrium in an infinite horizon model extends to a standard reputation model with incomplete information, a finite horizon, and a single debt relationship. In terms of the incomplete information, we allow a small amount of uncertainty about whether the government attaches a large disutility to not honoring its contracts. (As the reader will recall from the work on the chain store paradox by Kreps and Wilson 1982 and Milgrom and Roberts 1982, it is necessary to have some incomplete information like this in order to have a chance to support the reputation equilibria. For some related work in international economics, see Eaton 1992. $)^{2}$ We show that the spirit of the Bulow and Rogoff result holds: with a single debt relationship, reputation can support effectively zero debt.

We then turn to the main analysis and expand our partial reputation model, in which the debt relationship is modeled in isolation, to a general reputation model which includes all of a country's relationships. We capture this expanded view by adding to the simple model one other relationship. We focus on another relationship which has constant per-period benefits. We call it a domestic labor relationship, but, as noted above, it can be interpreted as one in which either foreigners or domestic agents are making up-front investments. We also show how with some minor modifications it can be interpreted as a mutual defense pact. We find that even if there is a vanishingly small amount of uncertainty about the type of the government, the unique equilibrium of our model has reputation 
supporting as much debt as there would be under full commitment. That is, we show that there are circumstances under which a general reputation can support large amounts of positive debt.

The main contribution of our paper is to exposit a model of a country's general reputation. Indeed, if the Bulow and Rogoff (1989b) paper is viewed as having killed the partial reputation models (and having laid the groundwork for the subsequent direct-sanctions approach adopted by Bulow and Rogoff 1989a, Armendarez de Aghion 1990, Fernandez and Rosenthal 1990, Fernandez and Kaaret 1992, and others), then this paper can be viewed as reviving the reputation approach. Moreover, if we accept Bulow and Rogoff's (1989b) argument that their assumption on saving is the empirically relevant one and English's (1996) historical analysis that direct sanctions are too small to support debt, then there is, currently at least, no other story besides ours for why there is debt.

It is important to point out that at the end of their article Bulow and Rogoff (1989b) briefly discuss an idea similar to ours. They discuss a trigger strategy model in which a country is playing a tariff supergame in which either raising tariffs or defaulting on foreign debts triggers a costly trade war. In this trigger strategy context, however, there is really no notion of a country's reputation per se and there is no particular reason for a trade war to be connected to defaulting on the debt: this is just one of a continuum of equilibria. More importantly, their punch line is that lending must be supported by direct sanctions. Ours is the opposite.

\section{AN ECONOMY WITH ONE TRUST RELATIONSHIP}

We begin with an incomplete-information economy that consists of two countries and lasts a finite number of periods. One country has a number of risk-neutral bankers. The other country is represented by the government, which has access to a country-specific investment project and needs to borrow resources to fund it. There are two types of government: a normal government and an honest government. A normal government is risk-neutral and discounts the future at rate $\beta$. An honest government has the same utility as the normal one except that it experiences a large disutility from breaking contracts. The type of the government is private information. Bankers hold subjective 
beliefs about what type the government is, and they update these beliefs after seeing the actions of the government. We will show that in this economy, reputation can support effectively zero debt. To show this, we set up and define a Bayesian equilibrium. We show that as the bankers' prior belief that the government is honest shrinks to zero in an appropriate fashion, the associated equilibrium converges to one with zero debt.

Specifically, in each period $\mathrm{t}, \mathrm{t}=0, \ldots, \mathrm{T}$, the economy has a perishable consumption-capital good. Bankers are risk-neutral, live for one period, have a discount factor $\beta$, and are endowed with a large amount of the consumption-capital good in each period. Without loss of generality, we suppose that each period has two bankers, who are denoted $i=1,2$. The normal government has these preferences:

$$
\sum_{t=0}^{T} \beta^{t} c_{t}
$$

where $c_{t}$ is the government's consumption in period $t$. The honest government has these same preferences except that if it fails to honor a contract it has signed, its utility is the expression in (1) minus a large positive constant $\mathrm{M}$. In each period $\mathrm{t}$, an investment of $\mathrm{x}_{\mathrm{t}+1}$ units in period $\mathrm{t}$ produces output of $\mathrm{A}_{\mathrm{t}+1} \mathrm{x}_{\mathrm{t}+1}$ units in period $\mathrm{t}+1$. Here $\mathrm{A}_{\mathrm{t}}$ is a deterministically fluctuating productivity parameter that specifies the investment project's gross return. For simplicity, we assume that

$$
A_{t}=\left\{\begin{array}{ll}
A, & \text { if } t \text { is odd } \\
0, & \text { if } t \text { is even }
\end{array}\right\}
$$

(Letting productivity fluctuate is an easy way to give the government an incentive to borrow. This simple pattern of fluctuations makes the resulting borrowing pattern simple, but is otherwise inessential.) The project has a maximal size of one in the sense that $x_{t} \leq 1$. Throughout the paper, we will assume that the discount factor satisfies this condition:

$$
\beta \mathrm{A}>1
$$


as well as $\beta<1$. The government is endowed with $x_{0}=0$ units of the consumption-capital good at the beginning of period 0 .

A precise description of the timing of events in the model is as follows. In each period t, the government starts with new output, $A_{t} x_{t}$, and the value of debt either owed or saved, $R_{t} b_{t}$, where $R_{t}$ is the gross interest rate from period $t-1$ to $t$ and $b_{t}$ is the amount borrowed by the government at $\mathrm{t}-1$. The government decides whether to repay old loans subject to this constraint:

$$
z_{t} R_{t} b_{t} \leq A_{t} x_{t}
$$

where $\mathrm{z}_{\mathrm{t}}=1$ corresponds to repayment by the government and $\mathrm{z}_{\mathrm{t}}=0$, to default. Each banker $\mathrm{i}=1$, 2 , having seen the default decision as well as the past actions of all agents, first offers the government a gross interest rate $\mathrm{R}_{\mathrm{t}+1}^{\mathrm{i}}$. Then, after bankers have seen each other's interest rate offers, they each offer a loan size $b_{t+1}^{\mathrm{i}}$. (By allowing bankers to condition their loan sizes on their competitor's interest rate offer, we avoid the possible nonexistence of equilibrium with pure strategies for lenders, as discussed in a related context by Jaffee and Russell 1976.) A loan contract $s_{t+1}$ is a pair $\left(R_{t+1}, b_{t+1}\right)$ that specifies a gross interest rate and a loan amount. Let $\mathrm{S}_{\mathrm{t}+1}$ denote the set of loan contracts offered. The government is thus offered loan contracts $s_{t+1}^{i}$ by bankers $i=1,2$, and so $S_{t+1}=\left(s_{t+1}^{1}, s_{t+1}^{2}\right)$. Faced with such a set of contracts, the government chooses a contract and randomizes if there are ties. The government also chooses how much to consume, $\mathrm{c}_{\mathrm{t}}$, and invest, $\mathrm{x}_{\mathrm{t}+1}$, subject to a constraint on the maximal size of the project,

$$
\mathrm{x}_{\mathrm{t}} \leq 1
$$

and on the government's budget,

$$
c_{t}+x_{t+1}-b_{t+1}=A_{t} x_{t}-z_{t} R_{t} b_{t}
$$

To build intuition, let us begin by examining an economy in which institutions are such that agents in both countries can commit to repaying their loans. Competition among bankers ensures that in each period $t$, the equilibrium gross rate of interest on loans is $R_{t}=\rho$, where $\rho \equiv 1 / \beta$. From (3), we know that the return on the project, A, is greater than $\rho$; hence, with such an interest rate in each 
even-numbered period, the government optimally borrows to fully fund the project. Thus, in each even-numbered period, starting with period 0 , the government borrows one, invests it, and consumes zero. In the next odd-numbered period, the project yields A units of output, out of which the government repays the banker $\rho$, consumes the rest $\mathrm{A}-\rho$, and borrows zero. The discounted value of utility under commitment is, thus,

$$
(\mathrm{A}-\rho)+\beta^{2}(\mathrm{~A}-\rho)+\beta^{4}(\mathrm{~A}-\rho)+\ldots=\frac{\mathrm{A}-\rho}{1-\beta^{2}} .
$$

Of course, given that the government has linear preferences and that the discount factor of the government $\beta$ satisfies $\beta=1 / \rho$, the timing of consumption by the government can be structured in a variety of ways to yield the same discounted value of utility.

Consider now the environment without such commitment. We set up and define equilibrium as follows. The history $\mathrm{h}_{\mathrm{t}}=\left\{\left[\mathrm{z}_{0}, \mathrm{~S}_{1}, \mathrm{~s}_{1}, \mathrm{x}_{1}, \mathrm{c}_{0}\right], \ldots,\left[\mathrm{z}_{\mathrm{t}-1}, \mathrm{~S}_{\mathrm{t}}, \mathrm{s}_{\mathrm{t}}, \mathrm{x}_{\mathrm{t}}, \mathrm{c}_{\mathrm{t}-1}\right]\right\}$ records past actions of the government and the bankers up to period t. A strategy for the government at $\mathrm{t}$ is a probability of repaying $\sigma_{t}^{i}\left(h_{t}\right), i=n, h$ (normal or honest), at the beginning of the period together with loan contract, investment, and consumption decisions denoted $s_{t+1}\left(h_{t}, z_{t}, S_{t+1}\right), x_{t+1}\left(h_{t}, z_{t}, S_{t+1}\right)$, and $c_{t}\left(h_{t}, z_{t}, S_{t+1}\right)$ made after both the realization of repayment decision $z_{t}$ and the offer of the new set of loan contracts $S_{t+1}$. A strategy for each banker $\mathrm{i}=1,2$ at $\mathrm{t}$ is an interest rate $\mathrm{R}_{\mathrm{t}+1}^{\mathrm{i}}\left(\mathrm{h}_{\mathrm{t}}, \mathrm{z}_{\mathrm{t}}\right)$ and a loan size $\mathrm{b}_{\mathrm{t}+1}^{\mathrm{i}}\left(\mathrm{h}_{\mathrm{t}}, \mathrm{z}_{\mathrm{t}}, \mathrm{R}_{\mathrm{t}+1}\right)$, where $R_{t+1}=\left(R_{t+1}^{1}, R_{t+1}^{2}\right)$. We let $S_{t+1}\left(h_{t}, z_{t}, R_{t+1}\right)$ denote the set of such contracts. Bankers also have a set of common beliefs, or priors, $\mathrm{p}_{\mathrm{t}}\left(\mathrm{h}_{\mathrm{t}}\right)$ that gives the probability of the government being honest conditional on the history.

A perfect Bayesian equilibrium is a set of strategies for the normal and honest governments and a set of strategies and beliefs for the bankers that satisfy the following conditions: (i) For each history, given the strategies and beliefs of the bankers from $t$ onward and given the strategies of the governments from $t+1$ onward, the strategies of the governments at $t$ maximize the governments' payoffs among the set of strategies that satisfies (4)-(6) and $s_{t+1}^{i}\left(h_{t}, z_{t}, S_{t+1}\right) \in S_{t+1}\left(h_{t}, z_{t}, R_{t+1}\right)$ for $i=n$, h. (ii) For each history, given the strategies of the governments, the strategy of the other banker at 
$\mathrm{t}$, and the beliefs of banker $\mathrm{j}$, the strategy of banker $\mathrm{j}$ maximizes this banker's payoffs for $\mathrm{j}=1,2$. (iii) Bankers' beliefs are updated according to Bayes' rule.

Notice that in the above setup, bankers are not allowed to default. One interpretation of this assumption is that bankers have a commitment device that commits them to honoring all contracts they sign. It will be clear that in any equilibrium, regardless of the government's past actions, if the government wants to save any amount $\left(\right.$ any $b_{t+1}<0$ ), then the bankers will oblige them and, moreover, competition among bankers will drive the interest rate on such savings up to $R_{t+1}=\rho$. We refer to these bankers as Swiss bankers in order to emphasize the feature that they are willing to let any government save with them regardless of the government's reputation.

We have shown in previous work (Cole and Kehoe 1995) that the level of borrowing in this economy is effectively zero. To do so, we used a standard (but complicated) backward induction argument to compute the equilibrium for this economy. We showed that if the initial prior and the initial capital were small enough, then the equilibrium value of utility and the initial borrowing level were both close to zero. To make this sense of closeness precise, we considered a sequence of economies in which the prior shrank to zero as the horizon length converged to infinity. More precisely, we proved this proposition:

PROPOSITION 1. Consider a sequence of economies indexed by the horizon length $T$, with $\beta<1$, in which the initial prior $p_{0}(T)$ converges to 0 as $T$ converges to infinity. Along this sequence, the equilibrium discounted value of utility converges to 0 , and the initial borrowing converges to 0 .

\section{AN ECONOMY WITH MULTIPLE TRUST RELATIONSHIPS}

In this section, we add to the model of Section 2 other relationships that involve trust. For another relationship to help support debt, we need misbehavior in the debt relationship to spill over and tarnish the government's reputation in the added relationship. It turns out that a small amount of incomplete information similar to that in Section 2 will generate such spillover in equilibrium. We 
also need the net benefits of maintaining a good reputation to be both large and persistent. We illustrate these conditions by means of some very simple examples. It will be clear that more elaborate examples can be constructed along the same lines.

Clearly, the most trivial way to add another trust relationship to the model above is to add another debt relationship with another group of bankers in another country which simply replicates the first. Let's do that. Let the information setup be the same as before except that the honest government suffers a loss in utility if it breaks contracts with either group of bankers. In any Bayesian equilibrium of the model, the honest government will honor all contracts with both groups if the utility cost of breaking them is sufficiently large. Thus, if either group of bankers sees a government break either type of contract, the bankers will know for sure that the government is not honest. A simple backward induction argument implies that bankers will never lend to a government they know is not honest. Hence, the normal government will either honor both contracts or break both, since breaking either causes the government to lose its reputation. Thus, reputation from the trust involved in one debt relationship spills over to the trust involved in the other and vice versa.

A moment's reflection should make it clear that even though there is spillover across the debt relationships, only the same level of effectively zero debt that could be supported with the single debt relationship can be supported here. Since both the benefits and the costs of defaulting in the model with two projects are simply twice what they are in the model with one project, the default decisions are unchanged. Hence, even with spillover from one debt relationship to another, no more debt can be supported than could be before.

While this exercise is useful, it is somewhat special because the added relationship is totally symmetric to the existing one. We will show that if the other relationship is the typical repeated relationship studied in almost all of the game theory literature, then large amounts of debt can be supported in equilibrium. 
Consider adding another trust relationship to the debt model. Let there be $\mathrm{N}$ agents, each of whom has a project. Each project requires an agent to put in some effort, and it produces A units of output. The opportunity cost of an agent's effort is $\omega$, which is measured in units of output at the end of the period. The government has the opportunity to tax the project's output at any rate $\tau \in[0,1]$. Let $\omega=(1-\tau)$ A denote the after tax return on a project. Let $\mathrm{N}_{\mathrm{t}}$ denote the number of projects actually undertaken where $\mathrm{N}_{\mathrm{t}} \leq \mathrm{N}$. (The assumption that the investment projects have the same productivity as the debt project in odd-numbered periods is for notational simplicity only.) We assume that

$$
\beta A \geq \omega .
$$

We can interpret these investment projects in a number of ways. The first is that they are undertaken by foreigners which require specific inputs by the foreigners. For example, a project may be an oil well drilled by foreigners. In each period the foreigners pump up A units of oil at an opportunity cost of $\omega$. The government taxes some of the output from the oil well. These projects can also be thought of as local investments by domestic citizens. For example, a domestic citizen may invest in setting up a tortilla shop, put in effort each period, and make output that the government may tax. More generally, these projects can be interpreted as any type of investment that involves upfront effort or cost for which the government can tax or confiscate the proceeds. Clearly we can also think of them as any domestic project which involves labor input and a future output. While we will keep these various interpretations in mind, we find it convenient to refer to these types of projects as labor projects and refer to those undertaking them as workers. We will also refer to the government as hiring workers and paying them a wage. Of course, in our other interpretations hiring workers corresponds to promising a tax rate which attracts investors, and paying a certain wage corresponds to levying a certain tax rate after the project is completed.

For the sake of intuition, note that under commitment, the allocations are as follows. In period 0 , the government borrows and invests one, hires $\mathrm{N}$ workers, and consumes zero. In period 1, the investment and labor projects yield a total of A + AN units of output, out of which the 
government pays the bankers $\rho$ and pays the workers $\omega \mathrm{N}$. The government borrows and invests zero and consumes $(A-\rho)+(A-\omega) N$. In period 2 and any even-numbered period after that, the labor project yields $\mathrm{AN}$, out of which the government pays the workers $\omega \mathrm{N}$ and consumes $(\mathrm{A}-\omega) \mathrm{N}$. The government also borrows one and invests it. Here, as in Section 2 with linear preferences and $\beta=$ $1 / \rho$, the timing of consumption by the government can be structured in a variety of ways to yield the same discounted value of utility.

Now consider the model without commitment. The timing of the model is the same as before, with these additions. In the beginning of each period, each of the large number of workers offers an employment schedule. Each worker i offers to supply $n_{t}\left(i, w_{t}\right)$ units of labor to the government for a promise of $\mathrm{w}_{\mathrm{t}}$ units of pay, where $\mathrm{n}_{\mathrm{t}}$ is either zero or one. Confronted with a continuum of such wage schedules, all of which are identical, the government announces some particular wage $\mathrm{w}_{\mathrm{t}}$ together with an employment cap $\mathrm{N}_{\mathrm{t}}$. The output of the project is realized immediately. After that, the government decides whether or not to honor its contracts with the bankers and the workers. We let $\mathrm{z}_{\mathrm{t}}^{\mathrm{b}}=1$ and $\mathrm{z}_{\mathrm{t}}^{\mathrm{n}}=1$ correspond to honoring the debt and labor contracts. The constraints faced by the government are

$$
\mathrm{z}_{\mathrm{t}}^{\mathrm{b}} \mathrm{R}_{\mathrm{t}} \mathrm{b}_{\mathrm{t}}+\mathrm{z}_{\mathrm{t}}^{\mathrm{n}} \mathrm{w}_{\mathrm{t}} \mathrm{N}_{\mathrm{t}} \leq \mathrm{A}_{\mathrm{t}} \mathrm{x}_{\mathrm{t}}+\mathrm{AN}_{\mathrm{t}}
$$

together with

$$
c_{t}+x_{t+1}-b_{t+1}=A_{t} x_{t}+A N_{t}-z_{t}^{b} R_{t} b_{t}-z_{t}^{n} w_{t} N_{t}
$$

and

$$
\mathrm{x}_{\mathrm{t}+1} \leq 1 \text { and } \mathrm{N}_{\mathrm{t}} \leq \mathrm{N} \text {. }
$$

In (10), we have assumed that the number of workers is $\mathrm{N}_{\mathrm{t}}$.

The specification of the governments is similar to that before. There are two types of government: a normal government and an honest government. A normal government is risk-neutral and discounts the future at rate $\beta$. An honest government evaluates consumption streams the same way as the normal government, but an honest government also assigns a large disutility to breaking any 
contract it has signed, that is, either the debt contract or the labor contract. In particular, we can write the preferences of an honest government as

$$
\left.\sum_{t=0}^{T} \beta^{t} c_{t}-\left(1-z_{t}^{b}\right) M^{b}-\left(1-z_{t}^{n}\right) M^{n}\right]
$$

where $\mathrm{M}^{\mathrm{b}}$ and $\mathrm{M}^{\mathrm{n}}$ are large positive numbers. (Recall that $\mathrm{z}_{\mathrm{t}}^{\mathrm{b}}=1$ and $\mathrm{z}_{\mathrm{t}}^{\mathrm{n}}=1$ correspond to honoring the debt and labor contracts and $\mathrm{z}_{\mathrm{t}}^{\mathrm{b}}=0$ and $\mathrm{z}_{\mathrm{t}}^{\mathrm{n}}=0$ correspond to defaulting on these contracts.) The type of the government is private information. Both bankers and workers hold subjective beliefs about what type the government is, and they update these beliefs after seeing the actions of the government.

The same logic we used above with two debt relationships should make clear here that in any Bayesian equilibrium of this model, the honest government will honor all debt and labor contracts if $\mathrm{M}^{\mathrm{b}}$ and $\mathrm{M}^{\mathrm{n}}$ are sufficiently large, which we will henceforth assume to be true. Thus, if a private agent, either a banker or a worker, sees the government default on either type of contract, the agent will know for sure that the government is not honest. A simple backward induction argument implies that workers will never work for, or bankers lend to, a government that they know is not honest. Hence, the normal government will either honor both contracts or default on both, since defaulting on either one causes the government to lose its reputation. Thus, the reputation from the trust involved in the debt relationship necessarily spills over to the trust involved in the labor relationship and vice versa.

One way to analyze the model's implications for government borrowing is to compute the equilibrium directly by backward induction. However, a more convenient way is to develop some simple properties of the equilibrium indirectly. To do that, we first backtrack a little: we consider a model that has only a labor project and develop in that model an expression for the value of reputation in the labor relationship alone. We then consider the model with both the debt and labor relationships. We use the result that losing trust in the debt relationship spills over to the labor relationship to show how the full commitment level of debt can be supported. 
Consider the model in which we set $x_{t}=b_{t}=0$ for all $\mathrm{t}$. The formal definition of a Bayesian equilibrium is similar to the one in the previous section; here we proceed more informally. In the Bayesian equilibrium that we consider, the workers' beliefs about the government are summarized by a conditional probability that the government is honest. We denote this conditional probability at $\mathrm{t}$ by $\mathrm{p}_{\mathrm{t}}$ and call it the reputation of the government. In this equilibrium, the history of past events at the beginning of period $t$ is summarized by the conditional probability $\mathrm{p}_{\mathrm{t}}$. The strategies of agents are allowed to depend on $\mathrm{p}_{\mathrm{t}}$ together with the actions that have already occurred within the period. Thus, the work decision of worker $\mathrm{i}$ can be written as $\mathrm{n}_{\mathrm{t}}\left(\mathrm{i}, \mathrm{w}_{\mathrm{t}}, \mathrm{p}_{\mathrm{t}}\right)$. The model's interesting equilibria turn out to involve the government randomizing, or mixing, over whether or not to honor its contract. Let $\sigma_{\mathrm{t}}^{\mathrm{n}}$ denote the probability that the normal government honors the contract. The equilibrium we compute has two requirements: At every possible state, each agent acts optimally, given the strategies and beliefs of other agents, and beliefs are updated according to Bayes' rule wherever possible. Since the honest government never defaults on contracts $\left(\sigma_{t}^{\mathrm{h}} \equiv 1\right)$, Bayes' rule implies that the probability that the government is honest at $\mathrm{t}+1$, conditional on honoring its contract at $\mathrm{t}$ (and all previous periods), is

$$
\mathrm{p}_{\mathrm{t}+1}=\frac{\mathrm{p}_{\mathrm{t}}}{\mathrm{p}_{\mathrm{t}}+\left(1-\mathrm{p}_{\mathrm{t}}\right) \sigma_{\mathrm{t}}^{\mathrm{n}}}
$$

In each period $\mathrm{t}$, each of the $\mathrm{N}$ workers will supply one unit of labor if the expected wage is greater than or equal to $\omega$. If the honest government always honors contracts and the normal government honors them with probability $\sigma_{t}$, then at an offered wage of

$$
\mathrm{w}_{\mathrm{t}}=\frac{\omega}{\mathrm{p}_{\mathrm{t}}+\left(1-\mathrm{p}_{\mathrm{t}}\right) \sigma_{\mathrm{t}}^{\mathrm{n}}},
$$

the workers will receive an expected wage of $\omega$. Hiring workers will only be profitable for the honest government if the wage rate is less than the return on the project, that is, if

$$
\mathrm{w}_{\mathrm{t}} \leq \mathrm{A}
$$


Backward induction works in this model exactly as it does in the standard Kreps-Wilson (1982) and Milgrom-Roberts (1982) models of the chain store paradox. Solving backward to period 0 gives the following value function:

$$
\mathrm{V}_{0}\left(\mathrm{p}_{0}, \mathrm{~T}\right)=\left\{\begin{array}{cc}
\sum_{\mathrm{s}=0}^{\mathrm{T}-1} \beta^{\mathrm{s}}(\mathrm{A}-\omega) \mathrm{N}+\beta^{\mathrm{T}} \mathrm{AN} & \text { if } \omega / \mathrm{A} \leq \mathrm{p}_{0} \leq 1 \\
\sum_{\mathrm{s}=0}^{\mathrm{T}-2} \beta^{\mathrm{s}}(\mathrm{A}-\omega) \mathrm{N}+\beta^{\mathrm{T}-1} \mathrm{AN} & \text { if }(\omega / \mathrm{A})^{2} \leq \mathrm{p}_{0}<\omega / \mathrm{A} \\
\vdots & \vdots \\
(\mathrm{A}-\omega) \mathrm{N}+\beta \mathrm{AN} & \text { if }(\omega / \mathrm{A})^{\mathrm{T}} \leq \mathrm{p}_{0}<(\omega / \mathrm{A})^{\mathrm{T}-1} \\
\mathrm{AN} & \text { if }(\omega / \mathrm{A})^{\mathrm{T}+1} \leq \mathrm{p}_{0}<(\omega / \mathrm{A})^{\mathrm{T}} \\
0 & \text { if } \mathrm{p}_{0}<(\omega / \mathrm{A})^{\mathrm{T}+1}
\end{array}\right\} .
$$

This value function corresponds to the following equilibrium behavior. In the lowest region, defined by $\mathrm{p}_{0}<(\omega / \mathrm{A})^{\mathrm{T}+1}$, no mixing probability is both high enough to give a wage $\mathrm{w}_{0}<\mathrm{A}$ and low enough to push up the next period's prior into the next-highest region. Hence, workers do not work at period 0. Workers do not revise their priors, and then $\mathrm{p}_{1}=\mathrm{p}_{0}$, and workers do not work at period 1 , and so on. The value of utility is, thus, zero. In the next-highest region, with $(\omega / A)^{T+1} \leq p_{0}<(\omega / A)^{T}$, workers work, and the government is just indifferent between currently defaulting on its contract and honoring it. Thus, the value of utility is AN. In the next-highest region, with $(\omega / A)^{\mathrm{T}} \leq \mathrm{p}_{0}<(\omega / \mathrm{A})^{\mathrm{T}-1}$, the government strictly prefers to honor its contract this period and start mixing the next period. Thus, today it gets $(\mathrm{A}-\omega) \mathrm{N}$ units of consumption; from tomorrow on, the value of its utility is AN; and its total utility is $(\mathrm{A}-\omega) \mathrm{N}+\beta \mathrm{AN}$. For the next-highest region, the government strictly prefers to honor the contract for two periods and then start mixing, which gives it a total utility of $(A-\omega) \mathrm{N}$ $+\beta(A-\omega) N+\beta^{2} A N$, and so on.

Consider now the equilibrium behavior for a fixed prior $\mathrm{p}_{0}$ as the time horizon lengthens. Suppose $\mathrm{k}$ is an integer such that

$$
(\omega / \mathrm{A})^{\mathrm{k}+1} \leq \mathrm{p}_{0}<(\omega / \mathrm{A})^{\mathrm{k}}
$$


Then the government honors its contracts for sure in the first $\mathrm{T}-\mathrm{k}$ periods. In periods $\mathrm{T}-\mathrm{k}+1$ through $\mathrm{T}-1$, it will mix, and in period $\mathrm{T}$, it will default. As $\mathrm{T}$ gets longer, so does the length of time that the government honors its contracts for sure, and in the limit, the government never defaults.

This equilibrium has a feature that we will use later. Given any initial prior $\mathrm{p}_{0}>0$, let $\mathrm{k}\left(\mathrm{p}_{0}\right)$ be the integer such that (17) holds. Thus, in period $\mathrm{T}-\mathrm{k}\left(\mathrm{p}_{0}\right)$, the government is just indifferent between defaulting on and honoring its contracts, and the value of either is AN. One period earlier, at $\mathrm{T}-\mathrm{k}\left(\mathrm{p}_{0}\right)-1$, the value of honoring is $(\mathrm{A}-\omega) \mathrm{N}+\beta \mathrm{AN}$, or

$$
\mathrm{AN}+(\beta \mathrm{A}-\omega) \mathrm{N}
$$

By assumption, $\beta \mathrm{A}>1>\omega$, so that as we move back one period, the value of honoring contracts strictly increases while the value of defaulting remains fixed at AN. Thus, there is a strictly positive gap of $(\beta A-\omega) \mathrm{N}$ between these values. Continuing in this manner, we see from (16) that j periods before $\mathrm{T}-\mathrm{k}\left(\mathrm{p}_{0}\right)$ the value of honoring contracts can be rewritten as

$$
\mathrm{AN}+\frac{\left(1-\beta^{\mathrm{j}}\right)}{1-\beta}(\beta \mathrm{A}-\omega) \mathrm{N}
$$

while the value of defaulting is simply AN. Thus, the gap between the value of honoring and the value of defaulting monotonically increases as we move back in time from $\mathrm{T}-\mathrm{k}\left(\mathrm{p}_{0}\right)$.

We will construct borrowing, investing, and repaying allocations which coincide with the full commitment levels for all but a fixed, finite number of periods at the end of the game. Given some $\mathrm{k}^{\prime}$, let these allocations specify that the government follow the full commitment allocations before $\mathrm{T}-\mathrm{k}^{\prime}$ and at $\mathrm{T}-\mathrm{k}^{\prime}$ switch to self-financing the investment project. More precisely, given some $\mathrm{k}^{\prime}$ chosen such that $\mathrm{T}-\mathrm{k}^{\prime}$ is odd for $\mathrm{t}=\mathrm{T}-\mathrm{k}^{\prime}$, let these allocations specify that out of total output A $+\mathrm{AN}$, the government repay bankers $\rho$ and pay workers $\omega N$. Now, instead of borrowing zero and consuming the rest, the government saves $1 / \rho$ and consumes the rest. In period $\mathrm{T}-\mathrm{k}^{\prime}+1$ and each even-numbered period thereafter, the government receives AN from the labor project and one from the savings. The government invests one, hires $\mathrm{N}$ workers, and consumes $(\mathrm{A}-\omega) \mathrm{N}$. In period $\mathrm{T}-$ 
$\mathrm{k}^{\prime}+2$ and each odd-numbered period thereafter, the government receives a total output of $\mathrm{A}+\mathrm{AN}$, repays bankers zero, pays workers $\omega \mathrm{N}$, saves $1 / \rho$, and consumes the rest, namely, $(A-1 / \rho)+(A-\omega N)$.

For what $\mathrm{k}^{\prime}$ can these allocations be supported in the reputation model with both a debt project and a labor project? To compute this number, ignore spillover for a moment, and consider only the direct costs and benefits of defaulting on the debt contract with the bankers. In any period $t \leq \mathrm{T}-$ $\mathrm{k}^{\prime}$, the net benefits of defaulting on the debt contract are simply the saving of funds used to repay the loan, namely, $\rho$. For $\mathrm{t}>\mathrm{T}-\mathrm{k}^{\prime}$, there are no loans, so the net benefits of defaulting are zero. Now add back in the spillover effects. For some given prior $\mathrm{p}_{0}$, if we set $\mathrm{k}^{\prime}=\mathrm{k}\left(\mathrm{p}_{0}\right)+1$, the difference between the value of honoring both debt and labor contracts and defaulting on them in period $\mathrm{T}-$ $\mathrm{k}^{\prime}$ is $(\beta \mathrm{A}-\omega) \mathrm{N}-\rho$. In any odd-numbered period before this, the net benefits of defaulting on the debt contract are the same, namely, $\rho$, while the gap between honoring and defaulting on the labor contract increases. In any even-numbered period, there is no debt and thus no benefit to defaulting. In any later period, there is no debt, so the net benefits of defaulting on it are obviously zero. Thus, if

$$
\rho<(\beta \mathrm{A}-\omega) \mathrm{N},
$$

then it is possible to support the full commitment allocations from period 0 through period $\mathrm{T}-\mathrm{k}^{\prime}$ with $\mathrm{k}^{\prime}=\mathrm{k}\left(\mathrm{p}_{0}\right)+1$. More generally, for any given $\beta$, let $\mathrm{j}(\beta)$ be the first integer such that the net benefits of defaulting on the debt contract are smaller than the net gains from paying the workers; namely,

$$
\rho<\frac{\left(1-\beta^{\mathrm{j}}\right)}{1-\beta}(\beta \mathrm{A}-\omega) \mathrm{N} .
$$

If $\mathrm{T}-\left[\mathrm{k}\left(\mathrm{p}_{0}\right)+\mathrm{j}(\beta)\right]$ is odd, let $\mathrm{k}^{\prime}=\mathrm{k}\left(\mathrm{p}_{0}\right)+\mathrm{j}(\beta)$, and otherwise, let $\mathrm{k}^{\prime}=\mathrm{k}\left(\mathrm{p}_{0}\right)+\mathrm{j}(\beta)-1$. Then, using the same reasoning as before, we can support the full commitment allocations up to period $\mathrm{T}-\mathrm{k}^{\prime}$.

Next consider the strategies in this equilibrium. For computational reasons, we have found it convenient to express these strategies as functions of the state variable $\mathrm{p}_{\mathrm{t}}$. Of course, the more general way of defining strategies in game theory is to define them as functions of the entire history 
of past actions of the players. It is obvious that for $\mathrm{t}<\mathrm{T}-\mathrm{k}^{\prime}$, the strategies of the normal government, the bankers, and the workers are such that if the government has never defaulted on either contract, the lenders and workers continue with their full commitment actions, while if it has defaulted, bankers do not lend and workers do not work. (Of course, for $\mathrm{t} \geq \mathrm{T}-\mathrm{k}^{\prime}$, these strategies are somewhat more complicated.) We summarize our discussion with

PROPOSITION 2. There exists a $\underline{\beta} \in(0,1)$ such that for all $\beta \in(\underline{\beta}, 1)$, the equilibrium allocations coincide with those under full commitment from period 0 through period $T-k^{\prime}$, where $k^{\prime}=k\left(p_{0}\right)+$ $j(\beta)$.

There is a precise sense in which the allocations in the economy with multiple trust relationships converge to the full commitment allocations even though the amount of uncertainty about the type of government becomes arbitrarily small. To understand that precise sense, consider the following:

Condition. The sequence of priors, $\mathrm{p}(\mathrm{T})$, satisfies

$$
(\rho / A)^{k(T)+1} \leq p_{0}(T)<(\rho / A)^{k(T)},
$$

where $k(T)$ converges monotonically to infinity as $T$ does and $T-k(T)$ converges to infinity.

Since $\rho / A<1$, clearly $\mathrm{p}_{0}(\mathrm{~T})$ monotonically converges to zero as $\mathrm{T}$ converges to infinity. Now consider a sequence of economies indexed by $\mathrm{T}$ and $\mathrm{p}_{0}(\mathrm{~T})$. Along such a sequence, the importance of the honest government is monotonically declining to zero. Notice that in a sense, the prior is shrinking to zero more slowly than the horizon length is growing to infinity.

Now consider a sequence of economies indexed by $T$ and $\mathrm{p}_{0}(\mathrm{~T})$, where $\mathrm{p}_{0}(\mathrm{~T})$ satisfies the above condition. Let $\underline{\beta}$ be such that (21) is satisfied for some finite $\mathrm{j}(\underline{\beta})$. Using (16) and the above analysis, we can show straightforwardly that the equilibrium value of utility converges to the full commitment level. 


\section{INTERPRETATIONS AND EXTENSIONS}

In this section we discuss other interpretations of the second relationship and we discuss the plausibility of assumptions behind the model.

In Section 2 we interpret the second trust relationship in a variety of ways. Each of these interpretations involves some type of up-front effort or investment that yields some output which the government could then seize or confiscate. Of course, there are other types of trust relationships, such as mutual defense pacts. These types of relationships are modeled slightly differently than the previous ones. Here we set up a simple model of a mutual defense pact.

Let the borrowing country and some other country, which may or may not be the lending country, be involved in a mutual defense pact. Refer to these countries as 1 and 2, respectively. Each country has a government that is either an honest type or a normal type. Let there be three exogenous states: country 1 by itself has a war, country 2 by itself has a war, and neither country has a war. Let the probabilities of these states be $\pi, \pi$, and $1-2 \pi$, respectively. (We assume that the probability that both countries have a war is zero.) If country 2 has a war, the government of country 1 can either help it or not help it. For the normal government of country 1 the cost of helping is e units of utility and the cost of not helping is zero. The payoff to the normal government of country 2 if it has a war and no help from country 1 is $\mathrm{W}_{\mathrm{N}}$, while if it has a war and help from country 1 the payoff is $\mathrm{W}_{\mathrm{H}}$. If country 1 has a war the payoffs to the normal governments of 1 and 2 are symmetric. The honest government of either country has payoffs such that it always helps when the other country has a war. Let $\left(\mathrm{p}_{1 \mathrm{t}}, \mathrm{p}_{2 \mathrm{t}}\right)$ be the priors that the governments of 1 and 2 are honest, and let $\left(\sigma_{1 \mathrm{t}}, \sigma_{2 t}\right)$ denote the probabilities that the normal governments of 1 and 2 help the other when one of them has a war.

It is easy to use similar arguments to those of Section 2 to show that given arbitrarily small priors $\left(\mathrm{p}_{10}, \mathrm{p}_{20}\right)$, there is an equilibrium of the following form. There is a fixed number of periods from the end of the game, say $\mathrm{k}=\mathrm{k}\left(\mathrm{p}_{10}, \mathrm{p}_{20}\right)$, such that at $\mathrm{T}-\mathrm{k}$ both players strictly prefer to help 
each other in a war and that at $\mathrm{T}-(\mathrm{k}+1)$ they are indifferent. As we move back from $\mathrm{T}-\mathrm{k}$ each period there is a gap between the value of helping then and following the equilibrium strategy thereafter and the value of not helping and getting a payoff of zero from then onward. The expected value of the flow benefits in each of these periods is

$$
\pi\left(\mathrm{W}_{\mathrm{H}}+\mathrm{W}_{\mathrm{N}}-\mathrm{e}\right)
$$

Using this we can show that the present value of the net gains from honoring the mutual defense pact grow larger as the horizon grows. We can use this fact to prove the analogue of Proposition 2.

Our main results depend on there being some reputation spillover across different arenas of behavior. We obtain these results by assuming a small amount of uncertainty about whether the government is an honest type. But how should this assumption be interpreted? We adopt an interpretation in the spirit of that given by Kreps and Wilson (1982) and Milgrom and Roberts (1982) in the chain store paradox literature. In a chain store game, in order for a monopolist to deter the entry of incumbents, these researchers allow a small probability that there is an irrational monopolist who fights any entrant. In their work, all of the interesting theorems are proven as limits as the probability of this irrational type goes to zero and the number of periods of the game goes to infinity. The interpretation these researchers give for their assumption is that there really is no irrational type; rather, this setup captures a vanishingly small uncertainty in the minds of the potential entrants that they may be facing a monopolist who plays tough. The normal monopolist understands that incumbents have this trivial amount of doubt, and it is exploited to build the monopolist a reputation. Indeed, Selten (1978) and Milgrom and Roberts (1982) think that the case of absolutely zero uncertainty in the minds of players (including uncertainty about other players possibly being uncertain) is unrealistic and, moreover, that this case generates predictions inconsistent with plausible behavior.

We interpret our uncertainty assumption in the same way. We think of the uncertainty about government honesty as being in the minds of agents who are in trust relationships with a country 
about the motives of the government for behaving well in any relationship. As long as the agents are not completely certain that there are no potential adverse consequences to the government in another relationship (or, at least, as long as this fact is not common knowledge to all other such agents), an equilibrium like ours should exist.

Finally, note that there are clearly other types of uncertainty about the types of government which would not generate reputation spillover. It should be obvious, however, that regardless of what other types of government exist, as long as at least one type attaches a large disutility to breaking both contracts, reputation will still support lending. Indeed, the equilibrium of the model then is similar to the analysis here.

\section{CONCLUSION}

We have developed a general reputation model of sovereign debt and showed that in it reputation can support large amounts of sovereign debt. The basic idea is that if a government is thought to be sleazy or untrustworthy in one arena of behavior, the country is thought to be sleazy or untrustworthy in other arenas as well. Hence, misbehavior in the debt arena has ramifications in many other arenas. In terms of the literature, we argue that if one accepts Bulow and Rogoff's (1989b) assertion that their assumption on saving is the empirically relevant one and English's (1996) historical analysis that direct sanctions are too small to support debt then, currently at least, ours is the only explanation of why there is sovereign debt.

The idea that an agent's reputation in one relationship may spill over into other relationships is certainly not new. In most of the literature, however, the spillover is such that actions of agents in one arena of behavior affect reputation in that arena only. In the debt literature, for example, if a government defaults on a loan, it ruins its reputation in the debt arena; in the industrial organization literature on entry deterrence, if an incumbent doesn't fight entry, it ruins the incumbent's reputation in the entry deterrence arena. Here we have shown that when spillovers stay within the debt arena, reputation cannot support lending. For reputation to support lending, a government's actions in the 
debt arena must spill over to a different arena which involves trust. We have shown how to interpret this other relationship as either foreign or domestic investment or as a mutual defense pact. There are many other interpretations as well. Viewed this way, the benefits of maintaining a good relationship in one arena cannot be calculated simply by looking at that arena alone. Instead, account must be taken of the ramifications in a variety of other arenas, which, at least on the surface, may not seem to be directly connected to the original arena, where misbehavior might occur. This basic idea of an agent's general reputation can be applied in many contexts.

Federal Reserve Bank of Minneapolis

University of Pennsylvania and Federal Reserve Bank of Minneapolis 


\section{Notes}

${ }^{1}$ Others have looked at other conditions for the existence of a reputation equilibrium. Pesendorfer (1992) considers a scenario in which the government must assemble an optimal portfolio from existing financial assets in the world market. Pesendorfer shows that even if the set of world assets is complete, adding the restriction that each asset in the portfolio must be held in a positive position may force the government to bear risk. The fear of bearing such risk may be sufficient to give the government an incentive to repay its debt. Mohr (1991) shows that a reputation equilibrium might exist in an overlapping generations model if a government can run a type of rational Ponzi scheme.

${ }^{2}$ Eaton (1992), following Diamond (1989), considers a reputation model which has two types of borrowers: "good" borrowers, for whom the lender can costlessly destroy output if they default, and "normal" borrowers, for whom the lender cannot do that. Eaton, however, assumes that there is no way to save after a default, so his model does not satisfy the Bulow and Rogoff (1989b) assumption on the ability to save. 


\section{REFERENCES}

ARMEndariz DE AGHion, B., “International Debt: An Explanation of the Commercial Banks' Lending Behavior after 1982," Journal of International Economics 28 (February 1990), 173-186.

AtKeson, A., "International Lending with Moral Hazard and Risk of Repudiation,” Econometrica 59 (July 1991), 1069-1089.

Bulow, J. AND K. Rogoff, “A Constant Recontracting Model of Sovereign Debt,” Journal of Political Economy 97 (February 1989a), 155-178.

, “Sovereign Debt: Is to Forgive to Forget?” American Economic Review 79 (March 1989b), 43-50.

Cole, H. L., J. Dow, AND W. B. English, "Default, Settlement and Signalling: Lending Resumption in a Reputational Model of Sovereign Debt," International Economic Review 36 (May 1995), 365-385.

Cole, H. L. and P. J. Kehoe, "The Role of Institutions in Reputation Models of Sovereign Debt," Journal of Monetary Economics 35 (February 1995), 45-64.

DiAmond, D. W., "Reputation Acquisition in Debt Markets," Journal of Political Economy 97 (August 1989), 828-862.

EAton, J., “Sovereign Debt, Reputation, and Credit Terms,” manuscript, Boston University, 1992.

EAton, J. AND M. Gersovitz, "Debt with Potential Repudiation: Theoretical and Empirical Analysis," Review of Economic Studies 48 (April 1981), 289-309.

ENGLish, W., "Understanding the Cost of Sovereign Default: American State Debts in the 1840's," American Economic Review 86 (March 1996), 259-275.

FERnANDEZ, R. AND D. KAARET, "Bank Heterogeneity and Debt Renegotiation,” International Economic Review 33 (February 1992), 61-78. 
Fernandez, R. And R. W. Rosenthal, "Strategic Models of Sovereign-Debt Renegotiations," Review of Economic Studies 57 (July 1990), 331-349.

Grossman, H. I. AND J. B. VAN HuYCK, “Sovereign Debt as a Contingent Claim: Excusable Default, Repudiation, and Reputation,” American Economic Review 78 (December 1988), 1088-1097.

JAFFEE, D. M. AND T. Russell, "Imperfect Information, Uncertainty, and Credit Rationing," Quarterly Journal of Economics 90 (November 1976), 651-666.

KLETZER, K. M., “Asymmetries of Information and LDC Borrowing with Sovereign Risk," Economic Journal 94 (June 1984), 287-307.

KREPS, D. M. AND R. B. WILSON, "Reputation and Imperfect Information," Journal of Economic Theory 27 (August 1982), 253-279.

MANUELLI, R., “A General Equilibrium Model of International Credit Markets,” manuscript, Stanford University, 1986.

Milgrom, P. AND J. RoBerTs, “Predation, Reputation, and Entry Deterrence,” Journal of Economic Theory 27 (August 1982), 280-312.

MoHR, E., Economic Theory and Sovereign International Debt (London: Academic Press, 1991).

PESENDORFER, W., “Sovereign Debt: Forgiving and Forgetting Reconsidered,” Discussion Paper 1016, Center for Mathematical Studies in Economics and Management Science, Northwestern University, 1992.

SElten, R., "The Chain Store Paradox," Theory and Decision 9 (1978), 127-159. Reprinted in A. Rubinstein, ed., Game Theory in Economics, International Library of Critical Writings in Economics, no. 5 (Aldershot, Harts, England: Elgar, 1990), 265-297. 